\title{
MJN ELECTIVE CESAREAN BIRTH: PROS AND CONS
}

\author{
Aisha Alshdefat ${ }^{1 *}$, Abdalla Alshdaifat ${ }^{2}$ \\ ${ }^{1}$ Department of Maternal and Child Health, College of Nursing, Sultan Qaboos University, Sultanate of Oman \\ ${ }^{2}$ Medical School, University of Lodz, Republic of Poland \\ *Corresponding Author's Email: alshdefat@squ.edu.om
}

\begin{abstract}
One of the women's rights and autonomy are to choose the mode of delivery. Elective cesarean is one of the delivery methods that the women can choose without medical reasons but will select the method if she is fully aware of the short- term and long-term effects of cesarean section versus vaginal birth. Opinion about the elective cesarean section as a method of delivery describes a combination of women's belief about her right to choose, feelings about vaginal delivery, and women's beliefs about body image. This position statement aims to discuss the issues of elective cesarean birth and the factors that have recently contributed to this debated choice. We must determine the costs, advantages, and liability matters that affect the birth mode recommendations.
\end{abstract}

\section{Keywords: Cesarean, Child Birth, Mode of Delivery}

\section{INTRODUCTION}

There are roughly 66,557 live births in the sultanate of Oman in 2013, out of which 11,822 were Caesarean Section(CS), and $27 \%$ of the total cesarean were elective. Cesarean birth on request can describe as a delivery carried out for non-health indications (Nygaard \& Cruikshank, 2003).

Pillai et al. (2016) revealed that the caesarian section (CS) rate in Oman increased gradually from $9.7 \%$ in 2000 to $15.7 \%$ in 2009 at Sultan Qaboos University Hospital(SQUH). According to the Health Information and Statistics Department-DG Planning and Studies under the Ministry of Health in Oman (2018), the rate of cesarean section deliveries in Oman increased from $9.7 \%$ in 2000 to $19.4 \%$ in 2018 of the total 89.071 childbirths (Omani and non-Omani) (MOH, 2018). More recently, elective cesarean increase due to perceptions that the CS is safer than vaginal delivery (Vaidyanathan et al., 2016).

There are different reasons why women choose cesarean as a method of delivery, usually driven by many factors (Nygaard \& Cruikshank, 2003). Cesarean section upon women's request is escalated due to fear of risk at the time of child birth, previous CS, and bad experience with last vaginal delivery.

There is no proper justification for higher CS rate by
$10-15 \%$, according to a study by the World Health Organization (WHO, 2015). Based on the research of WHO in 2009, the rate of Cesarean section has significantly increased, worldwide (Norum \& Svee, 2018).

Abdulrahman et al. (2019) conclude that the CS levels in the United Arab Emirates (UAE) is above the global average and the average in Asia. Based on literature body Wingert et al. (2019), many countries in which more than half of the births were in the caesarean section whereas in Egypt it is 55.5\% in 2014, Brazil $55.5 \%$ in 2015 , Turkey $53.1 \%$ in 2015 , and Venezuela $52.4 \%$ in 2013 (Betran et al., 2016).

This position statement is discussed in this review article regarding the risks and benefits of cesarean delivery to provide health care professionals with the necessary training to advise women.

\section{Argument regarding Mode of Delivery}

Mode of delivery is a common subject for a lengthy debate. Many morbidities were linked to one delivery mode or another. Choosing the mode of delivery changes from one woman to another; it's affected by many factors such as the fear of pain, previous delivery experiences, cultural beliefs, and the concern about taking care of the children at the last minute.

Mode of the delivery debate arise from the women's 
empowerment to make her decision regarding her body, and the impact of both vaginal birth and caesarian section delivery on their body and sexual functions.

\section{Pros of Vaginal Birth}

Globally, the evidence for the benefits of vaginal birth delivery based on the literature review. Vaginal birth is a normal process that can be mentally grueling to the mothers. But the benefits of having a vaginal birth include shorter resting period and stay at home, fast recovery compared with cesarean delivery, and the baby is exposed to birth canal bacteria that boosted the immune system. Therefore, the delivery through the natural process helps to eject the amniotic fluid in the baby's fluid, which makes it easy for him to breath (Betran et al., 2016). In case of normal delivery, the baby will receive immediate skin to skin contact and direct breastfeeding, which increases the bonding between the mother and the baby shortly after the delivery.

A short stay at the hospital in case of normal birth will lower the family stress and gives reassurance. A shorter hospital stay means that the mother and the baby get back home faster, reducing the stress levels for the entire family. Natural delivery also gives reassurance of the future deliveries (Olza-Fernández et al., 2014).

\section{Cons of Vaginal Birth}

In case of vaginal birth there is a risk that the skin and tissues around the vagina can stretch and tear during a vaginal delivery while the fetus moves through the birth channel. Stretching and tearing is serious, a woman might need stitches, or this may cause pelvic muscle weakness or damage the regulation of urine and bowel function (Betran et al., 2016). Some studies also have show that women who have vaginal delivery are more likely to have bowel or urinary incontinence issues than women who have had C-sections. They may also be more susceptible to urine leakage while coughing, sneezing, or laughing (Olza-Fernández et al., 2014).

\section{Pros of Caesarean Section}

Proponents define that the women have the right to choose the mode of the delivery; they consider it as the respect of women's autonomy to control their body. Proponents believe the cesarean section to be safe (Zakerihamidi et al., 2015).

They claim that the vaginal delivery have a high risk of the urine incontinence and sexual dysfunction, there is chances that baby may suffer due to oxygen shortage during childbirth, and chance of infants trauma when the child go through the birth channel.

\section{Cons of Caesarean Section}

The cesarean section sometimes causes damages to the bladder and bowel, increase of maternal bleeding, anesthesia complications, blood clots, and deep vein thrombosis. Additionally, studies have shown that women undergoing caesarian sections are with a high risk of infertility, ectopic pregnancy, and women who had two previous caesareans section will prefer delivery by cesarean section for ever (He et al., 2016).

Moreover, the cesarean section is a major operation associated with risk, like excessive bleeding, surgical site infection, deep vein thrombosis, reaction to the anesthesia, and bladder injury that increase the maternal mortality and morbidity rate beside the risk for the baby including respiratory complication and accident cut to the skin. Moreover the surgery would make a mother dizzy, she will keep away from her baby and could delay breastfeeding after she delivers (Olza-Fernández et al., 2014).

The cost of Caesarean section is higher than vaginal birth resulting in increases of financial burden on the family (He et al., 2016).

\section{A Position Statement}

Current authors are against cesarean birth without medical necessity. In the present study risk and complication of the cesarean delivery in case of both mother and infant are taken into consideration. Besides, Olza et al. (2014) reported that the bonding between the mother who chooses normal delivery would have a strong bonding with her infant more than the mother who opting for cesarean birth (Olza et al., 2014).

\section{CONCLUSION}

This position statement aims to present proponents and opponent opinions regarding vaginal birth versus cesarean section and articulates recommendations to reduce unnecessary caesarian section.

This position statement elucidates the following recommendations for the clinical practice:

1. Awareness and counseling of women about vaginal birth, Restorative measures, and the advantages and risk during labor must to explained to all expecting mothers.

2. Discuss the reasons behind the request for a cesarean section like previous unpleasant experiences, 
anxiety, fear, post-traumatic stress disorder, or insufficient information.

3. Examine vital evidence of elective cesarean birth and participate in discussions or debates based on the doctor, culture, and individual.

4. Medical workers must discuss the patient data acquired from practice regarding cesarean birth rates, vaginal birth after cesarean, and elective cesarean.

5. Caregivers must work in groups for proper assistance for appropriate counceling and to spread awareness. This will result in better health and well being of the mothers.

6. Follow the WHO guidelines and recommendations to reduce unnecessary cesarean section (WHO, 2012).

\section{Conflict of Interest}

The author(s) declare(s) that there is no conflict of interest regarding the publication of this article.

\section{Ethical Clearance}

This article does not contain any studies involving human participants performed by any of the authors.

\section{Conflict of Interests}

The authors declare that they have no conflict of interest.

\section{ACKNOWLEDGEMENT}

The authors are thankful to the institutional authority for completion of the work.

\section{REFERENCES}

Abdulrahman, M., Abdullah, S. S., Alaani, A. F. K., AlAbdool, N. H., Sherif, F. E. Y., Ahmed, Z.S., Al-Rawi, H.I., Hubaishi, N.M., Tahlak, M.A.R. \& Carrick, F.R. (2019). Exploring Obstetrical Interventions and Stratified Cesarean Section Rates Using the Robson Classification in Tertiary Care Hospitals in the United Arab Emirates. Revista Brasileira de Ginecologia e Obstetricia, 41(03), pp 147-154.

Annual Health Report: Ministry of Health (2018). Chapter-Seven: Directorate: Utilization of Health Services. Retrieved from: https://www.moh.gov.om/en/web/statistics/annual-reports

Betran, A.P., Torloni, M.R., Zhang, J.J., Gulmezoglu, A.M. \& WHO Working Group on Caesarean Section (2016). WHO Statement on Caesarean Section Rates. BJOG: An International Journal of Obstetrics and Gynaecology, 123(5), pp 667-670.

He, Z., Cheng, Z., Wu, T., Zhou, Y., Chen, J., Fu, Q. \& Feng, Z. (2016). The Costs and their Determinant of Cesarean Section and Vaginal Delivery: An Exploratory Study in Chongqing Municipality, China. BioMed Research International, 2016, 5685261 .

Norum, J. \& Svee, T.E. (2018). Caesarean Section Rates and Activity-Based Funding in Northern Norway: A ModelBased Study Using the World Health Organization's Recommendation. Obstetrics and Gynecology International, $2018,6764258$.

Nygaard, I. \& Cruikshank, D.P. (2003). Should all women be offered an elective cesarean section? Obstetrics \& Gynecology, 102,pp 217-219.

Olza-Fernández, I., Gabriel, M.A.M., Gil-Sanchez, A., Garcia-Segura, L.M. \& Arevalo, M.A. (2014). Neuroendocrinology of childbirth and mother-child attachment: The basis of an etiopathogenic model of perinatal neurobiological disorders. Frontiers in Neuroendocrinology, 35(4), pp 459-472.

Pillai, S.A., Vaidyanathan, G., Al-Shukri, M., Al-Dughaishi, T. R., Tazneem, S., Khan, D., El-Tayeb, S. \& Mathew, M. (2016). Decisions to Perform Emergency Caesarean Sections at a University Hospital: Do obstetricians agree? Sultan Qaboos University medical Journal, 16(1), e42-e46.

Vaidyanathan, G., Al-Shukri, M., Al-Dughaishi, T. R., Tazneem, S., Khan, D., El-Tayeb, S. \& Mathew, M. (2016). Decisions to Perform Emergency Caesarean Sections at a University Hospital: Do Obstetricians Agree? Sultan Qaboos University MedicalJournal, 22(2833), pp 1-5. 
Wingert, A., Hartling, L., Sebastianski, M., Johnson, C., Featherstone, R., Vandermeer, B. \& Wilson, R. D. (2019). Clinical interventions that influence vaginal birth after cesarean delivery rates: Systematic Review \& MetaAnalysis. BMC Pregnancy and Childbirth, 19(1), pp 529.

World Health Organization (WHO) (2015). WHO Statement on Caesarean Section Rates. Department of Reproductive Health and Research, World Health Organization, Geneva, Switzerland. Retrieved from : https://apps.who.int/iris/bitstream/handle/10665/161442/WHO_RHR_15.02_eng.pdf;jsessionid=8473C12112 30048A31E6772289AA9C5B?sequence $=1$

World Health Organization. (2018). WHO recommendations non-clinical interventions to reduce unnecessary caesarean sections. World Health Organization: Sexual and reproductive health. Department of Reproductive Health and Research, World Health Organization, Geneva, Switzerland.

Zakerihamidi, M., Latifnejad Roudsari, R. \& Merghati Khoei, E. (2015). Vaginal Delivery vs. Cesarean Section: A Focused Ethnographic Study of Women's Perceptions in The North of Iran. International journal of community based nursing and midwifery, 3(1), pp 39-50. 